REVISTA DE DERECHO UNED, núm. 6, 2010

\title{
FUNDAMENTOS ÉTICOS Y TEÓRICOS DE LOS DERECHOS AMBIENTALES
}

\author{
Cayetano NúÑEz Rivero \\ (UNED) \\ AleXander LuZardo Nava \\ Universidad Central de Venezuela (UCV)
}

\begin{abstract}
Resumen: Las bases éticas y teóricas de los Derechos Ambientales y Transgeneracionales emergieron con fuerza en la década de los años setenta del pasado siglo, desde entonces, comenzando con la Declaración de Estocolmo, la constitucionalización de los citados derechos no ha cesado; en el presente trabajo se analiza el fundamento teórico de los mismos, mediante una revisión de las diversas fuentes doctrinarias, provenientes de las diferentes ramas de las ciencias sociales y jurídicas.
\end{abstract}

Palabras Clave: constitución, derecho ambiental, ecología, antropología antropcentrismo.

Abstract: The ethical and theoretical foundation of environmental and transgenerational laws, emerged with force in the seventies of the last century. Since then, starting with Stockholm's declaration, the constitutionalization of the cited laws has not ceased. In the present study we analyze their theoretical foundation through a review of the diverse source of doctrines, coming from the different branches of social and judicial sciences.

Key words: constitution, environmental law, ecology, anthropology, antropocentrisme.

Sumario: 1. Introducción.-2. El Determinismo Biológico Geográfico Ambiental.-3. Las Ciencias Sociales, el Derecho y el Ambiente.-4. Paradigma Antropocéntrico.-5. Paradigma Ecológico.-6. El Derecho Ambiental y Transgeneracional. 


\section{INTRODUCIÓN}

El fundamento teórico de los derechos ambientales y transgeneracionales, nos obliga a una revisión de las diversas fuentes doctrinarias, teóricas, provenientes de las diferentes ramas de las ciencias sociales, jurídicas, legislativas y constitucionales; asumimos en consecuencia una perspectiva interdisciplinaria ${ }^{1}$.

Varias disciplinas son consideradas en su aporte al desarrollo de un enfoque ecoantropológico, síntesis del paradigma antropocéntrico y del paradigma biocéntrico o ecológico, presentes en la historia del pensamiento social, económico, jurídico y de las ciencias naturales.

La cosmovisión dominante ha sido aquella que concibe que la humanidad ha avanzado hacia un control y dominio de la naturaleza, como expresión del progreso, la civilización y el desarrollo, asociada a la cosmovisión procedente del judeo-cristianismo, pero también asumido por otras, tales como el Islam, incluyendo algunos pueblos indígenas como los Mayas, Aztecas e Incas, a diferencia de otras civilizaciones como las amazónicas, que han convivido en forma armoniosa con su ambiente, por lo menos hasta época reciente.

La cosmovisión judeo-cristiana, queda reflejada en el siguiente texto bíblico: extraído del Génesis (...) les dijo «sed fecundos, multiplicaos y llenad la tierra. Infundiréis temor y miedo a todos los animales de la tierra; todas las aves del cielo y todos los peces del mar, quedan a vuestra disposición», "vosotros pues sed fecundos y multiplicaos, extendeos por la tierra y dominen en ella».

En el texto citado existe una voluntad de poder y dominio sobre la naturaleza por decisión de un ser superior, que al crear a los hombres les ordena que todas las especies vivas queden "a su disposición», sin embargo, también plantea como proyecto una alianza con «vosotros y vuestros futuras descendencias y con todo ser vivo que os acom-

1 Diversos autores son fuente obligatoria en el desarrollo del pensamiento Interdisciplinario hacia la creación de una nueva ética ecológica, entre los cuales registramos a Manhana Ghandhi, Aldo Leopold, Jay Forrester, Donella Meadon, Roberto Constanza, Edgar Morín, Roberth Goodlan, Hernan Daly, Emilio Moran, William Cotton, Riley Dunlap, Henry Lefebre, Esteban Mosonyi, Enrique Leff, Ernesto Mayz Vallenilla, Phillip Saint Mar, Martín Mateo, Guillermo Cano, Francisco Meaño, Raúl Brañes, entre otros, procedentes de los distintos campos disciplinarios: Filosofía, Derecho Ambiental, Sociología, Antropología y Ecología, además de las fuentes procedentes de los procesos socio-políticos, jurídicos, parlamentarios, actividades de las organizaciones no-gubernamentales ambientales y de pueblos originarios que han convivido armoniosamente con la naturaleza y en muchos casos aun conviven, en un largo proceso de ensayo y error, particularmente los pueblos amazónicos. 
pañe: las aves, los ganados y todas las alimañas que hay con vosotros, con todo lo que ha salido del arca, todos los animales de la tierra ${ }^{2}$. Desde el propio Génesis se observa, al mismo tiempo que existe un discurso antropocéntrico, el reconocimiento de la diversidad biológica y la posibilidad de un pacto o alianza para evitar el «exterminio de la vida» «dijo Dios: esta es la senda de la alianza para las generaciones perpetuas pongo entre la tierra y yo, entonces se verá el arco de las nubes y me acordaré de la alianza que media entre vosotros, todo ser vivo y yo y no habrá más aguas diluviales para exterminar la vida» ${ }^{3}$.

Podríamos inferir una cosmovisión, en la cual predomina la voluntad de poder de un creador sobre los hombres y demás seres vivos, del ambiente en general, pero en cuyo proyecto existe la posibilidad o la decisión de restablecer los vínculos, luego del «pecado original», que ha provocado la ruptura. En esta segunda línea del Judeocristianismo es posible derivar también una ética transgeneracional primaria.

\section{EL DETERMINISMO BIOLÓGICO GEOGRÁFICO AMBIENTAL}

En la historia de la humanidad el denominado «determinismo biológico, geográfico y ambiental» ha ocupado un lugar relevante, influyendo en la conformación de una determinada concepción del mundo y en la constitución de sistemas científicos, tecnológicos, sus referencias espaciales y sistemas jurídicos.

Las teorías sobre las interacciones hombre-naturaleza más antiguas que conocemos, se remontan a las culturas mesopotámicas y védicas, aunque será en la civilización griega, donde encuentren un ambiente acogedor. Las teorías de los humores, que provenía de las culturas védicas y que había alcanzado un alto grado de sofisticación en la India, tuvieron un desarrollo aun mayor en Grecia ${ }^{4}$.

Fue el filósofo griego, Empedocles De Agrigento (490-435 a.C.), quien en sus dos poemas «De la Naturale y Las Purificaciones», las presenta como una revelación de carácter esotérico, referida al origen de todas las cosas. Estas tienen "cuatro raíces» inscritas en el pensamiento presocrático y que retoma Aristóteles: el fuego, el aire, el agua y la tierra.

\footnotetext{
2 Genesis, Biblia de Jerusalén, Editorial Porrua, 1998, p. 23.

3 Genesis, Biblia de Jerusalén, Editorial Porrua, 1998, p. 23.

4 Ver G. S. Kira y J. E. Raven. Los Filósofos Presocráticos Gredor, 1969 y Resumen de Fragmentos. Empédocles De Agriento. Hacia 490-435 a.C., Diccionario de las Mil Obras, Claves del Pensamiento - Denis Huisman. Editorial Tecnos, Madrid, 1997.
} 
La teoría de los cuatro elementos ejerció una influencia importante en el pensamiento antiguo, a partir de estos cuatro elementos se construye una cosmogonía completa. La unión de los elementos fuego, aguas, aire y tierra, creaba todo lo viviente, mientras que la falta de armonía entre los mismos era responsable de las enfermedades. El pensamiento biológico de los griegos tuvo una influencia aún mayor en la obra de Hipócrates. Las teorías de éste incorporaron los cuatro elementos de Empedocles agregando cuatro cualidades que estarían presentes en todas las cosas: el frío, el calor, la sequedad y la humedad. Junto con los cuatro humores (Sangre, flema, bilis amarilla y bilis negra) estos ocho factores servían para diagnosticar todos los estados de salud, enfermedad y personalidad 5 .

Hipócrates le dio gran importancia a la alimentación en la obtención de una buena salud, de allí su célebre frase «que tu alimento sea tu medicina, que tu medicina sea tu alimento", la cual ha ejercido tanta influencia en la historia de la medicina y que sigue siendo paradigma en los naturistas, vegetarianos, naturópatas y médicos naturistas. Las teorías de los cuatro elementos y de los cuatro humores de Empédocles e Hipócrates continúa hoy vigente, en términos gnerales en el pensamiento occidental.

Hipócrates intenta explicar las causas de las enfermedades, particularmente durante sus viajes por el Mediterráneo Oriental, como consecuencia de la influencia de los factores ambientales, haciendo énfasis en el clima, e incorporando también, la diversidad humana y sociocultural de los pueblos, pero las restringe al concepto de raza:

"Cuando una raza en un áspero país montañoso, a una altitud considerable, con unas lluvias cuantiosas y con marcadas diferencias entre estaciones, entonces sus gentes serán de gran talla, bien acostumbrados a la audacia y la valentía y con no poca ferocidad y brutalidad en su carácter. Por otra parte, en tierras bajas, sofocantes, con prado son más flemáticos que coléricos. La valentía y la audacia no son parte de su carácter, aunque se pueden adquirir con la adecuada formación» ${ }^{6}$.

El paradigma de Empedocles-Hipócrates, puede considerarse como el primero que se registra en la historia del pensamiento social, por lo menos ha sido el de más larga duración, aproximadamente dos milenios.

${ }^{5}$ Emilio Moran (2000). La Ecología Humana, p. 29. F.C.E.

6 Véase al respecto, Luis Lemkom (2006). Sociología Ambiental. Icaria Editorial. Madrid, p. 30. 
Para Hipócrates, las condiciones atmosféricas, las aguas, la alimentación, son la causa de la salud o enfermedad de las personas, influyendo con esta tesis en el desarrollo de la salubridad pública, la higiene y la medicina, que establecieron relación directa entre los problemas sanitarios y el ambiente. Hasta el siglo XIX sus tesis se mantienen en la medicina y cultura occidental, específicamente la propuesta de la existencia de cuatro humores (las dos bilis, la flema y la sangre) con el carácter temperamental humano (cuatro temperamentos: colérico, flemático, melancólico y sanguíneo).

El mundo helénico y romano, heredaron gran parte de los planteamientos de Hipócrates de Cos, sobre la diversidad de culturas y la influencia que en ellas ejercían los factores ambientales especialmente el clima. Los antiguos griegos, el imperio romano y la civilización árabe, consideraron que el clima, era un factor importante en su supuesta percepción de pueblos supuestamente civilizados y superiores, ya que la ubicación geográfica así lo determinaba.

Santo Tomás de Aquino, mantuvo la idea hipocrática con leves modificaciones, de tal manera que el determinismo geográfico-ambiental sobreviviría mil años después de Hipócrates «Un clima templado es más propicio a la fuerza necesaria para la guerra con la que la sociedad humana vela por su seguridad».

Diversos autores han sido importantes en la formación del pensamiento determinista biológico geográfico-ambiental, así tenemos el caso del filósofo inglés John Locke, quien sostenía que el ambiente juega un papel decisivo en las diferencias de comportamiento individuales y nacionales. El hombre no solo era el producto de la creación divina, sino también la naturaleza.

El historiador y filósofo islámico andaluz Ibn Khaldoun (13321406), también recibió la influencia del pensamiento hipocrático. Era necesario, según él, estudiar la base geográfica de la cultura, incluyendo el clima, como un factor que permite explicar el carácter de los seres humanos. Asimismo los factores ambientales y los alimentos, tienen una repercusión sobre los hábitos sociales y condiciones médicas.

«Las zonas quinta, cuarta y tercera ocupan una posición intermedia. Tienen mucha templanza, que es el justo medio. La cuarta zona, la más cercana al centro, es todo lo templado que puede ser. El físico y el carácter de sus habitantes son templados en relación con el alto nivel requerido por la composición del aire en que viven ${ }^{7}$.

${ }^{7}$ Ibn Khaldoun, contribuyó decisivamente al desarrollo de las ciencias sociales en el Islam y la obra reseñada es The Muqaddimah, Princeton University, editado en 1967, publicado originalmente en el año 1377. 
Nicolás Maquiavelo en el Renacimiento, sostiene que el clima y el suelo ejercen una influencia relajante sobre el carácter.

Jean Bodino trató de establecer vínculos entre los diferentes sistemas legales y los procesos históricos en términos de astrología y ambiente, maneja los conceptos de Hipócrates sobre los humores, además de un componente racista que acompaña a casi todos los pensadores de la época al referirse a los pueblos no occidentales. "Este salvajismo (de las gentes del sur) deriva en parte de ese despotismo que es un sistema vicioso de formación que los apetitos indisciplinados han creado en el hombre, pero se debe mucho más a una falta de proporción en la mezcla de los humores. Y ello a su vez procede de los elementos afectados por las fuerzas externas. Los elementos están perturbados por la energía de los cuerpos celestiales, y el cuerpo humano está envuelto en los elementos».

El determinismo físico-espacial de Bodino, le otorga vida a los planetas en ciertas áreas geográficas de la tierra.

Las zonas del sur, serán influenciadas por Saturno de características más religiosas, mientras que Júpiter incide sobre las zonas templadas y civilizadas.

Montesquieu, en la Ilustración, es uno de los pensadores que asume el determinismo geográfico-ambiental con más énfasis, en el proceso de elaboración de las leyes siendo reconocido como el mejor exponente especialmente por la explicación del desarrollo de los sistemas jurídicos.

Para Montesquieu, el clima y en menor medida el suelo, determinan el carácter o personalidad de un pueblo o nación. En su libro «El Espíritu de las Leyes», dice que las leyes «deben estar relacionadas con el entorno físico del país; con el clima helado, abrasador o templado, con la calidad del terreno, su situación y su extensión». "Los climas distintos que han dado lugar a los diversos modos de vida han formado los diversos tipos de leyes».

Para Montesquieu, existe una correlación entre el clima y el suelo con el tipo de la personalidad, que influye sobre la estructura social y finalmente es la estructura social la que determina el tipo de leyes y la legislación del país.

Para este autor el clima y el calor, incidieron sobre los órganos y estos tienen que ver con las conductas de las personas.

Montesquieu, fundamentó su teoría sobre criterios racistas, tal como se demuestra en el siguiente párrafo del El Espíritu de las Leyes 
«Los indios son cobardes por naturaleza; hasta con hijos de los europeos nacidos en la india pierden el arrojo propio de su clima».

Este determinismo basado en supuestas observaciones científicas, es una muestra de la manera cómo los prejuicios, las creencias, los mitos, las percepciones personales o las dominantes en una época determinada llegan a formar parte de los denominados paradigmas científicos ${ }^{8}$.

Sería un error afirmar que Montesquieu estudia la realidad recurriendo exclusivamente a la temperatura, así cuando enuncia tesis geográficas-ambientales, también toma en cuenta la naturaleza del suelo, la disponibilidad de agua, la distancia del mar, la existencia de los puertos naturales y la distribución de las masas de tierra y de agua; las costumbres morales y las normas de gobierno.

Para Montequieu la regla del clima es menos rígida en virtud del avance de la civilización, aunque «el imperio del clima es el primero y el más poderoso de todos los imperios».

La percepción del mundo se hace cada vez más compleja a partir del siglo XV, cuando se producen los viajes de europeos por los territorios africanos y americanos, lo que repercutió en el conocimiento de nuevos mundos naturales y socioculturales, caracterizados por la exuberancia de su biodiversidad, marcada por una mayor cercanía a la línea del Ecuador.

Las transformaciones ambientales, económicas, sociales, culturales, vinculadas a la actividad comercial entre Europa y los territorios de ultramar, van a impactar no solo a América, sino también a la propia Europa, ampliándose también el intercambio entre diversas culturas y modos de vida.

Probablemente esa diversidad biológica, que va a ser sometida al reconocimiento y estudios de exploradores, funcionarios e investigadores, contribuye a reforzar la importancia de los determinantes geográfico-ambientales, tales como Buffon, quien resaltó la presencia del hombre en toda la faz de la tierra «aunque subordinado al poder de la naturaleza».

8 «Esta observación confirma lo que he estado diciendo, es decir, que en los países fríos las glándulas nerviosas están, menos expandidas: calan profundamente en sus vainas y están protegidas por la acción de los objetos externos; en consecuencia, no tienen sensaciones tan vivas. En los países fríos hay muy poca sensibilidad por el placer; en los países templados hay más; en los países cálidos, la sensibilidad es exquisita». 
Rousseau en su obra Emile, sostiene que a través de la educación son posibles los cambios sociales y del ambiente natural o modificado, "... la inconstancia de Europa no deja tiempo para que actúen los factores naturales, y en que se talen bosques y se desecan las marismas, en las que las tierra es más generalmente cultivada aunque menos cabalmente; de manera que las mismas diferencias entre naciones ya no pueden detectarse solo en las características físicas».

En el siglo XVIII, ya se detecta un mayor interés por el impacto del hombre sobre la naturaleza, que va a contribuir al desarrollo del "conservacionismo» vinculado al desarrollo de la ciencia y los viajes de conquista y expansión del capitalismo en proceso de internacionalización y como respuesta a la creciente depredación, herencia también de prácticas recocidas que caracterizaron por ejemplo la civilización helénica y romana, en las cuales fue común la desmedida explotación de la biodiversidad animal, asociada al hedonismo o al el ejercicio del poder, con sacrificio de animales y seres humanos.

Kant es otro pensador importante del determinismo geográfico, aunque es más conocido por su obra filosófica, es un autor de primera línea en el desarrollo de la geografía alemana, sobre todo en la geografía física y las relaciones entre sociedad y ambiente.

Para Kant la incidencia de las acciones humanas sobre el ambiente, son de gran importancia. El Paradigma Hipocrático, se reflejó también en este autor, para quien el clima desempeñaba un papel importante en el carácter nacional y las diferentes culturas. Kant es pues, una figura central en el avance de la geografía, aunque es evidentemente más conocido por su contribución a la filosofía.

Durante casi dos mil años el Paradigma Hipocrático fue dominante, aún con la llegada de las religiones monoteístas (judíos, cristianos, islámicos). Es apenas en el siglo XIX cuando se comenzó a resquebrajar este paradigma.

También es necesario destacar la obra de Alexander Von Humbold ${ }^{9}$, considerado por algunos como el fundador de la geografía moderna, quien realizó una monumental investigación del mundo tropical cuyas características y potencialidades difundió por todo el mundo, luego de sus expediciones que incluyen al continente sudamericano, y que al decir del geógrafo chileno-venezolano Pedro Cunil «sirvió decisivamente en el inicio de la geografía moderna. Las obras

9 En su obra Cosmos; Alejandro de Humbolt dice que «El cuadro general de la naturaleza que pretendo delinear sería incompleto sino me aventurara a trazar algunos de los rasgos...». 
de Humbolt van a ser conocidas en Estados Unidos y Europa entre 1810 y 1860 con la misma frecuencia que hoy se consulta a la Enciclopedia Británica.

En el siglo XIX comienzan a institucionalizarse las ciencias sociales y humanas en las universidades europeas con la creación de cátedras, departamentos e institutos de investigación. El Derecho ya poseía una larga historia y su vinculación con el ambiente se fundaba en los viejos principios del Derecho Romano sobre los bienes comunes y del Derecho Natural), «Es Derecho Natural el que la naturaleza enseñó a todos los animales, en efecto este derecho no es exclusivo del género humano, sino de todos los animales que nacen en el ciclo, en la tierra y en el mar...».

En el siglo XIX con las obras de Saint Simon, Edgar Taylor, Herbert Spencer y Lewis Morgan, comienza a desarrollarse la Sociología y la Antropología, como disciplinas académicas universitarias. Sin embargo, va a ser la Geografía, la que nos expresa esta tendencia, primero protagonizada por organizaciones no-gubernamentales de divulgación científica, como la Real Sociedad de Geografía de Inglaterra o los desarrollos vinculados al conocimiento y dominio del territorio, incluyendo las tesis de la Geopolítica Expansionista, algunos de cuyos nombres más destacados son Friedrich Ratzol (1844-1904) con su obra Antropogeografia y Política Geográfica. Karl Haushofer (1869-1946) que ejercieron gran influencia en las tesis geográficas de Adolfo Hitler.

Para el filósofo Hegel la naturaleza y la historia forman parte de una totalidad que es la realidad. La estructura de la realidad, es intrínsicamente directa, y el propósito de la filosofía es exponer conceptualmente la dialéctica de lo real, su estructura lógica interna. Para Hegel «la naturaleza es como ella es; y sus cambios son, por el contrario, solamente repeticiones, su movimiento solamente en curso circular. Inmediatamente su acción [la del espíritu] es conocerla», conocerla en su mecanicidad y circularidad respectivas. Lo contrario sucede en la historia, con el espíritu, en donde la negatividad y la innovación son lo más esencial. Para Hegel, no puede haber una dialéctica de la naturaleza, la dialéctica es algo que compete al trabajo, propiamente al trabajo humano y en consecuencia a la historia y a la sociedad $^{10}$.

Para Carlos Marx, el tema ambiental no formó parte esencial de su discurso, aunque su compañero de labores intelectuales y políticas

10 G. W. Hegel, La Razón en la Historia. 
Federico Engels expresó que el hombre surge de la naturaleza: «por nuestra carne, nuestra sangre y nuestro cerebro pertenecemos a la naturaleza, nos encontramos en su seno». Asimismo afirmó «no nos dejemos llevar del entusiasmo ante nuestra victorias ante la naturaleza. Después de cada una de estas victorias la naturaleza toma venganza». Pero es obvio que en ellos dominó la idea de dominio de la naturaleza y el desarrollo intensivo de las fuerzas productivas y el carácter inexorable y unilineal del progreso, inspiración de los socialismos reales que se constituyen en el siglo XX, a partir de la instauración de la Unión Soviética en 1917.

\section{LAS CIENCIAS SOCIALES, EL DERECHO Y EL AMBIENTE}

Las Ciencias Sociales y el Derecho, mantuvieron durante muchos años una relación distante con los temas ambientales, imbuidas por una concepción antropocéntrica, debiendo destacarse en los primeros sociólogos su larga lucha por crear un campo de estudio propio y una epistemología distinta a la de las ciencias naturales, explicable en su primera época, pero en revisión hoy a la luz de los nuevos criterios y convergencias transdisciplinarias. En la década de 1970 surge la denominada «Sociología de la Cuestión Medioambiental» promovida por los autores norteamericanos: Samuel Klausner, quien en 1971 publicó «El Hombre y El Medio Ambiente». El autor utiliza por primera vez la expresión "Sociología Medioambiental», mientras que con William Cotton y Riles Dunlap se desarrollan los parámetros que permiten definirla como nueva rama de la Sociología que estudia la interacción entre el ambiente y la sociedad. Se avanzó en el análisis de las relaciones entre clase social y la degradación ambiental, en el nuevo contexto, a pesar de la resistencia de la sociología establecida a tratar los temas ambientales, comprensible por la dependencia de la visión occidentalista fortalecida con el portentoso desarrollo industrial, urbano y el alejamiento del campo por parte de las ciudades modernas, que se consideraron independientes de sus entornos biofísicos. En los fundadores de las ciencias sociales las referencias a la influencia de los factores físicos y biológicos son muy débiles, consolidándose entonces una corriente de rechazo a estas «variables» como explicaciones de los fenómenos sociales.

Las características físicas eran relevantes solo si los actores participantes las percibían y definían como tales, es decir, se transforman en hechos. Así, la perspectiva de la «definición social» junto al constructivismo de Emile Durkhein, contribuyeron a que los científicos 
sociales ignoraran el entorno físico. «La influencia de estas tradiciones disciplinarias se pueden resumir así: el legado Durkheniano del antirreduccionismo, sugería que el entorno físico debía ignorarse mientras que el legado del alemán Marx Weber sugería que podía ignorarse porque no era importante para la vida social ${ }^{11}$. Según Durkheim «solo lo social puede explicar lo social».

Para los seguidores de la tradición sociológica incorporar el ambiente y sus procesos a las definiciones sociológicas, significaba asumir la postura de «los deterministas ambientales», cuestión esta que ya no se justificaba, si bien se podría justificar en los orígenes de esta disciplina. Esta posición del reduccionismo social, hizo que la Sociología permaneciera anclada, en un constructivismo interno (especie de endo-epistemología), mientras que otras disciplinas como la Antropología habían comenzado a plantearse los problemas ambientales, como parte de su dinámica.

La temática ambiental trasciende el marco disciplinario en el Derecho, la Sociología, la Antropología y hasta la propia Ecología, para asumir el reto del Paradigma Inter y Transdiciplinario. Según el venezolano Marcel Antonorsi en su obra Tecnología Suave. No cabe definir fronteras entre las diversas ciencias sociales y la ecología humana. «La situación es de una gran interpenetración y colaboración, que quizás apunta hacia una síntesis teórica...» ${ }^{12}$.

Para Edgar Morin en su libro «El Método, La Naturaleza de la Naturaleza»(2001)... La Ciencia Antroposocial necesita articularse a la ciencia de la naturaleza y esta articulación requiere de una reorganización de la estructura misma del saber. Todo conocimiento, incluso el más físico, sufre una determinación sociológica. En toda ciencia, incluso, en la más física, hay una dimensión antroposocial. De golpe, la realidad antroposocial se proyecta e inscribe en el corazón mismo de la ciencia física ${ }^{13}$.

Las relaciones del clima global con las civilizaciones, los procesos ecológicos, los movimientos tectónicos de la tierra, el proceso de hominización, el conocimiento científico interplanetario y los saberes milenarios, demandan una reconstrucción del método científico clásico, cuyos aportes han sido de gran significación para la humanidad,

11 Dunlap Riley (1997). Evolución de la Sociología del Medio Ambiente. Editorial McGraw-Hill. Caracas, Bogotá, México, p. 15.

12 Marcel Antonorsi Blanco, Tecnología Suave, Monte Ávila Editores, Caracas, 1981, p. 219.

13 Edgar Morin (2001). El Método, La Naturaleza de la Naturaleza. Editorial Cátedra. Madrid. 
ponderando también sus daños y potenciales amenazas. Esta nueva perspectiva postcientífica encuentra en la crisis ambiental global un «objeto complejo» de investigación que ya se expresa aproximadamente desde 1957, hasta nuestros días, en nuevos instrumentos científicos que inauguran la era espacial (trasbordadores espaciales, viajes a otros astros, ingeniería genética, telecomunicaciones, interactividad) las cuales van más allá de la globalización. La comprensión y manejo de la realidad social, planetaria e intergaláctica nos plantea nuevos desafíos.

\section{PARADIGMA ANTROPOCÉNTRICO}

William Cotton y Riley Dunlap han realizado una importante contribución para la conformación del campo de una Sociología Ambiental, asumiendo una crítica del denominado Paradigma del Exencionalismo Humano (PEH). Proponen como alternativa el desarrollo de un Paradigma Ecológico que se opone al reduccionismo. «Estos supuestos parecen representar un «Paradigma» $O$ «Lente» fundamental a través de la que la mayoría de los sociólogos ven el mundo. Cotton y yo afirmamos que estos supuestos se dan por sentados en tan gran medida que virtualmente nunca se hacen explícitos; pero claramente influyen en la práctica de la Sociología y explican el lento reconocimiento de nuestra disciplina del significado de los problemas medioambientales ${ }^{14}$.

El Paradigma del Exencionalismo Humano resalta la naturaleza excepcional de la especie humana, derivada de nuestra experiencia cultural, el lenguaje, la organización social y la tecnología, con una presencia irrelevante del mundo físico, de la Biosfera. «Nuestra disciplina se fundó sobre un conjunto de supuestos fundamentales o paradigma que condujo a la mayoría de los Sociólogos, al margen de su orientación teórica particular (funcionalismo, marxismo, interaccionismo) a considerar a las sociedades humanas como si estuvieran exentas de contriciones ecológicas. Como consecuencia del acento sobre las características excepcionales de los humanos, a mediados del siglo $X X$, la mayoría de los sociólogos ignoraban totalmente el entorno biofísico, como si la existencia de las sociedades humanas ya no dependiera de él» ${ }^{15}$.

Las ciencias sociales desde sus orígenes en el siglo XIX con SaintSimon, Augusto Comte, Herbert Spencer, Carlos Marx, Emile Durk-

14 Riley Dunlap (2001), ob.cit., p. 16.

15 Riley Dunlap (2001), ob.cit., p. 18. 
hem, Max Weber, asumieron y desarrollaron la idea de progreso y del evolucionismo sociocultural, presente en la Economía, la Sociología, la Historia, la Antropología y el Derecho, aunque es justo reconocer que en el caso de la Antropología, se abrieron espacios para la formulación de una concepción multilineal del desarrollo histórico y los aportes de la Ecología Cultural de Julián Steward ${ }^{16}$; Leslie White y Claude Levi-Strauss .

Manfred Stanley, asume como un logro fundamental de las ciencias sociales, esa autonomía absoluta de los «determinantes físicos». «Si buscamos una explicación, una sola frase, que denotara cuál ha sido el logro principal de la ciencia social hasta la fecha, una respuesta clara sería la sustitución progresiva de las explicaciones que acentúan la influencia determinada de la naturaleza física por las explicaciones socioculturales» ${ }^{17}$.

Un destacado autor norteamericano Daniel Bell, critica el planteamiento del Club de Roma, descartando la idea de «los límites físicos del crecimiento» ya que según él, de existir límites, éstos serían más bien límites sociales que físicos.

Para Roberth Nisbet, la oposición de los movimientos pacifistas y ecológicos al uso de la energía nuclear, significa una pérdida de la fe en el progreso "no se trata de una escasez ni peligro de la fuente de energía, sino de la pérdida de la Fe».

Si bien es cierto que el desarrollo de la teoría social desde Marx, Durkheim y Weber, representa un avance por disociar la estructura y el proceso social de las analogías biológicas, el despojo de las consideraciones ecológicas y biológicas de la teoría social, ha sido otro error.

William Cotton, dice que en la obra de Durkheim «La División del Trabajo Social», se pueden derivar las raíces de la ecología humana. Se refiere a la división entre sociedades de solidaridad mecánica y solidaridad orgánica, vinculando a su concepción del desarrollo histórico y la relación de las distintas sociedades con el entorno, pero nosotros apreciamos en Durkheim, la exclusión de las consideraciones ambientales.

16 Julian Steward (1992). El concepto y el Método de la Ecología Cultural en Antropología (Lecturas. Selección editada por Paul Bañan, Mar Blazer. Editorial McGrawHill. México DF).

${ }^{17}$ En Robert Nisbet (1979). The rope of progress public opinión. N. ${ }^{\circ}$ 2, junio y julio, New York, pp. 2-6, 55. 
Para Anthony Gidden «las preocupaciones ecológicas no encajan en las tradiciones [derivados de estos tres padres fundadores] incorporados a la Sociología, y no sorprende que los sociólogos de hoy encuentren difícil desarrollar una evaluación sistemática de ellos» ${ }^{18}$.

En las ciencias sociales y humanas, en su alejamiento del tema ambiental, ha influido su larga lucha por independizarse y construir un campo teórico-epistemológico propio, sin embargo, el campo de la Sociología Ambiental particularmente la obra de Dunlap y Cotón se ha consolidado como área de investigación en Estados Unidos, gran parte de Europa y en países asiáticos, especialmente Japón, tal como se puede observar en los programas de los Congresos de la Asociación Internacional de Sociólogos, los Congresos Internacionales Americanistas y otros eventos internacionales. Estos eventos han contribuido a promover y difundir la discusión en el ámbito universitario.

El autor francés Lucien Goldmann ${ }^{19}$ en su libro Las Ciencias Humanas y la Filosofía (1972) aborda el tema de especificidad de la epistemología de las ciencias sociales. Goldmann hace énfasis en este proceso, al igual que otros autores como Michael Lowy, que originalmente permearon los textos y seminarios de metodología y teoría social, incidiendo en casi todas las escuelas de Ciencias Jurídicas, Políticas y Sociología, Antropología y Economía ${ }^{20}$.

También ejerció una influencia determinante el marxismo clásico y el estalinista así como otras versiones con su clasismo extremo. Las determinaciones económicas y "Clases Obreristas», coparon las teorías sociales con prescindencia de los temas ecológicos. Prevaleció por décadas un proletariado-centrismo y un burge-centrismo, unido

\footnotetext{
18 Anthoni Gidden (2000). En Defensa de la Sociología. Alianza Editorial. Madrid.

19 «En realidad, dice Golmann que la diferencia entre las condiciones de trabajo de los físicos, químicos y fisiólogos y la de los sociólogos o los historiadores no es de grado, sino de naturaleza» Lucien Golman, Las Ciencias Humanas y la Filosofía. Ediciones Nueva Visión 1972, pp. 25-26. Sin embargo, cabe destacar que existen importantes referencias institucionales como la inclusión en el Primer Plan de Ciencia y Tecnología de Venezuela del 5 al 12 de julio del año 1975 que desarrolló el capítulo: La Ecología y la Planificación del Desarrollo. La Alternativa del Desarrollo. Ya el 1973 el Profesor y Economista Petrolero (UCV) Francisco Mieres publica con el título «Crisis Ecológica, Crisis Energética y Ciencias sociales», Cuadernos de la Sociedad Venezolana de Planificación, N. ${ }^{\circ}$ 111-112, abril-mayo 1973, pp. 41 y 45.

20 En el caso venezolano cuestión esta que se comprueba con sólo revisar los programas de estudio particularmente desde 1970, en los cuales, por cierto, se eliminaron asignaturas como Ecología y Geografía Humana, luego del llamado proceso de «Renovación Académica» (1969-1971). Precisamente cuando estaba emergiendo el nuevo paradigma ecológico se eliminaron en los nuevos Planes de Estudio disciplinas fundamentales para la revisión de su discurso clásico del desarrollo y la comprensión de las nuevas realidades.
} 
al eurocentrismo, no solo en Europa y EE.UU., sino también en Latinoamérica, y Venezuela, expresados por el positivismo, el marxismo, el funcionalismo, en sus distintas versiones.

La Escuela de Frankfurt, Alemania ejerció una gran influencia a partir de 1968, a través de las obras de Max Horkheines, Teodoro Adorno y Herber Marcuse quienes sostenían en su «teoría crítica» que solo un cambio radical en la teoria y en la práctica pueden generar cambios en una sociedad moderna, especialmente en el descomunal desarrollo tecnológico. Critican incluso el marxismo y su tesis de la inevitable revolución del proletariado. Asumen la crítica al positivismo y desde su constitución como Escuela en 1923, en Alemania y luego en Estados Unidos, donde Marcuse ejerce gran influencia en los movimientos estudiantiles, Hippie y movimientos pacifistas antinucleares. Sin embargo ya Herber Marcuse había escrito algunos de sus obras como Razón y Revolución (1936), Eros y Civilización (1956) y El Movimiento Soviético (1958), que tuvieron gran presencia en el mundo académico en la década de 1970. La segunda época tuvo como autor más representativo a Jurgen Heberman con su obra Teoría y Praxis (1963), Conocimiento e Interés (1968).

Es de destacar, una línea distinta en la obra El Manifiesto Diferencialista (1970) del Autor Francés Henry Lefebre que ejerció gran influencia en la academia occidental, siendo parte del nuevo torrente de ideas que confluyen en los nuevos paradigmas que cuestionan el economicismo y los "poderes homogenizantes» que los describe como «modelos, aparatos, tendencias centralista, ideologías» (el productivismo, el crecimiento ilimitado $)^{21}$.

Las opiniones de Lefebre, procedentes del marxismo renovador, constituyen una crítica importante en las ciencias sociales y políticas, comenzado por el stalinismo y al propio Marx. Se trata según sus propias palabras «Acabar con la indeferencia que existe (en el plano teórico) entre crecimiento y desarrollo es el primer objetivo de este manifiesto» ${ }^{22}$.

${ }^{21}$ Henry Lefebre El Manifiesto Diferencialista. Editorial Siglo XXI. También son referencias fundamentales como Ignacy Sachs que publica diversos trabajos entre 1970-1976 relacionado con el ambiente, tecnologías suaves, ecodesarrollo y etnodesarrollo. En 1970 publica Selección de Técnicas: Problemas y Políticas para América Latina, Boletín Economico para América Latina, $1^{\text {er }}$ semestre 1970, pp. 1-33; ecodesarrollo (1974) CERES, Vol 7 (6), noviembre-diciembre 1974, pp. 8-12; Ambiente y Estilos de Desarrollo (1975) Revista de Comercio Exterior. Sachs baza sus tesis desde su cátedra en la Escuela Práctica de Altos Estudios, de París-Centro Internacional de Investigaciones Sobre Ambiente y el Desarrollo.

${ }^{22}$ Henry Lefebre (1976), ob.cit., p. 20. 
El Paradigma antropocéntrico o del exencionalismo humano parte de los supuestos de que las personas son radicalmente diferentes a los seres vivos de la tierra, son dueños absolutos de su destino, con oportunidades ilimitadas sobre la tierra.

La imagen de las sociedades humanas, que destacan estos supuestos realza la naturaleza «excepcional» de nuestra especie derivada de nuestra herencia cultural, incluido el lenguaje, la organización social y la tecnología. Dunlap lo denomino originalmente «Paradigma del Excepcionalismo Humano».

El mismo autor aclara que no se trata de negar que el Homo Sapiens sea una especie excepcional, pero no al extremo de negar la presencia de los principios y criterios o constricciones ecológicas. Dunlap y Coton cambiaron el nombre por el de «Paradigma del Exencionalismo Humano».

\section{PARADIGMA ECOLÓGICO}

El nuevo Paradigma Ecológico ${ }^{23}$ que compartimos con Cotton y Dunlap podría resumirse en los siguientes términos:

${ }^{23}$ En la historia del pensamiento ecológico es fundamental la obra «La Primavera Silenciosa» (1962) de la bióloga y escritora norteamericana Raquel Carson, considerada como la gran obra precursora del movimiento ambiental. Algunos autores la ubican como el libro más influyente de los últimos cincuenta años. Carson escribió en 1951 «El mar que nos rodea». También comparte este honor, según nuestro criterio, el libro «Los Límites del Crecimiento» (Forreste, Meadon), el famoso Informe del Club de Roma. En 1972 desató la polémica internacional. El club fue fundado por el empresario italiano Aurelio Pecci, con un grupo de aprox. 100 personalidades de diversos países. En 1970, deciden realizar el estudio dentro del gran proyecto sobre la condición humana (Proyect on the predicament of man kina). Las tesis del informe de 1972 son: 1) El mundo puede considerarse como un sistema, 2) El sistema puede llegar al colapso a mitad del siglo XXI si continúan las tendencias actuales, 3) Para prevenir el colapso se debe iniciar una inmediata disminución del crecimiento económico que lleve al equilibrio en un periodo relativamente corto. También es necesario rescatar los aportes de la conferencia preparatoria para el año europeo de la Conservación de 1970, que se remonta al surgimiento en 1968 del Council for Envifonmental Education (Consejo de Educación Ambiental del Reino Unido) que plantea desde esa época una visión interdisciplinaria en el ámbito de la educación ambiental y señala un concepto de ambiente en el cual «los electos naturales, rurales y urbanos del ambiente están inextricablemente ligados y son interdependientes». Esta perspectiva va a estar presente en las políticas de países como Suecia, Francia, Alemania que desarrollaron lineamientos políticos de pedagogía ambiental y leyes, siendo particularmente intensa en los años 1968-1972. Ya desde 1949 la UNESCO planteó la importancia de los problemas ambientales, siendo el año 1968 de gran relevancia en los programas ambientales. La UNESCO, celebra en Paris entre el 9 y el 19 de noviembre la primera 
1) Aunque los humanos tienen características excepcionales (cultura, tecnología), siguen siendo una de las muchas especies implicadas en una relación de interdependencia con el ecosistema global.

2) Los asuntos humanos están influidos no sólo por los factores sociales y culturales, sino también por intrincados vínculos y de retroalimentación con la red de la naturaleza. Los humanos viven en, y son dependientes de un entorno biofísico que impone fuertes restricciones físicas y biológicas a los asuntos humanos.

3) La inventiva de los seres humanos y los poderes derivados de ella, ampliaron los límites de su capacidad, pero las leyes ecológicas no pueden ser revocadas.

Disciplinas como la sociología concentraron sus esfuerzos en la industrialización, la burocracia, el Estado, el suicidio, las clases sociales y estratificación, pero obvió o soslayó, la conexión con la Biosfera.

Se forjaron técnicas y metateorías que parecían prescindir de referentes con el mundo real, por otro lado se separa el mundo social del mundo natural, generando un tipo de conocimiento y una intervención sobre la naturaleza, que pone en peligro las bases biológicas y ecológicas de la vida y de toda forma de civilización.

La biología y la ecología clásica, redujeron la temática ambiental sólo a especialidades o reductos técnicos, que impedían cualquier vínculo con la sociedad y la cultura, aún reconociendo el inmenso aporte que han representado al desarrollar el modelo orgánico y sistémico que hoy forma parte del patrimonio intelectual. Los conceptos de órgano, función, estructura proveniente de la biología fueron incorporados por Herbert Spencer a las ciencias sociales y extendido a casi todas las disciplinas científicas y el lenguaje común. Para Henry Lefebre "Los conocimientos tan poderosos, tan especializados, han engendrado un desconocimiento general. La coexistencia del genocidio con una seguridad obsesiva del saqueo de la naturaleza terrestre con la explotación de los espacios deshabilitados, desconcierta más que deja

\footnotetext{
reunión del Congreso Internacional del Programa del Hombre y la Biosfera (Programa MAB) con la participación de 30 países y de diversas organizaciones internacionales, tales como la organización de las Naciones Unidas para la Agricultura y la Alimentación (FAO), la Organización Mundial de la Salud (OMS), la Unión Internacional para la Conservación de la Naturaleza (UICN). En la declaración de principios de la MAB de la UNESCO se establece un programa interdisciplinario de investigación que atribuyo especial importancia al método ecológico en el estudio de las relaciones entre la humanidad y el medio ambiente.
} 
traslucir una armonía ¿El progreso? Desde hace tiempo se distingue poco de la regresión ${ }^{24}$.

La crítica a la clásica idea de progreso, desarrollo y civilización cruza las diversas orientaciones disciplinarias y el establecimiento político y económico, convergiendo el movimiento ambiental, los movimientos pacifistas, antinucleares, grupos de profesores y científicos de las universidades, nuevas organizaciones políticas, organizaciones indígenas y ONGs, defensoras de los derechos indígenas, que progresivamente van impactando en el discurso político y jurídico, tanto en los países industrializados, como en los no industrializados y en los organismos internacionales, amén de las universidades y organizaciones empresariales y políticas, que condujo incluso, a la formación de partidos verdes en Europa que llegan a formar parte de alianzas locales y nacionales en el poder tales como Italia, Bélgica, Francia y en Alemania, donde han participado en el gobierno con el partido socialdemócrata.

Debe quedar claro que el conocimiento posee una incidencia múltiple; sus fuentes en nuestros días no son solo las universidades ya que se han diversificado los factores generadores constituyendo una red que produce y recrea nuevos conocimientos. El mismo desarrollo y masificación de la educación y la difusión promueve bifurcación creativa, cuestión esta que tiende a multiplicarse en corporaciones empresariales, centros de poder, organizaciones no gubernamentales, individualidades, etnias, grupos familiares, religiosos y políticos de cualquier tipo con acceso a recursos financieros y el propio conocimiento, ello plantea inmensas posibilidades, aunque también peligros.

Las posibilidades tienen que ver con la democratización del conocimiento, la participación social y cultural del poder y los peligros se refieren a la emergencia de grupos terroristas y fundamentalistas con posibilidades de acceder a las armas nucleares y bacteriológicas.

\section{EL DERECHO AMBIENTAL Y TRANSGENERACIONAL}

El Derecho comienza a producir un cambio significativo en la década de 1970, específicamente con la Conferencia de las Naciones Unidas sobre Medio Humano del año 1972 realizada en Estocolmo, Suecia, catalogado como el nacimiento del Derecho Ambiental Sis-

\footnotetext{
${ }^{24}$ Henry Lefebre (1970), ob.cit., p. 31.
} 
témico que tiende a superar el paradigma conservacionista por un paradigma ecológico el cual se va a expresar de una u otra forma en las distintas constituciones políticas de iberoamérica, España (1978), Brasil (1988), Colombia (1991) y Venezuela (1999).

A la UNESCO, corresponde una labor pionera fundamental desde 1949, cuando aborda la temática ambiental. En 1971, el programa el hombre y la biosfera (MAB) planteó como objetivo general «proporcionar los conocimientos fundamentales de ciencias naturaleza y de ciencias sociales necesarios para la utilización racional de la conservación de los recursos de la biosfera y para el mejoramiento de la relación global entre el hombre y el medio...». La Conferencia de la ONU, celebrada en Estocolmo, va a estar precedida por la reflexión teórica y política de la reunión de expertos celebrada en Founex, Suiza del 4 al 12 de Junio de 1971, con participación de representantes de todos los continentes, que producen el famoso Informe Founex, donde se planteó la situación de crisis global y la necesidad de asumir un modelo integral de desarrollo, basado en indicadores no solo cuantitativo sino también cualitativo. Entre los temas abordados por Founex se encuentran: a) El agotamiento de los recursos; b) La contaminación biológica; c) La contaminación química; d) La perturbación del medio físico; e) El deterioro social. El informe Founex plantea la relación pobreza ambiente, presente en las Conferencia de Estocolmo y Río de Janeiro de la ONU en 1971 y 1992. La Declaración sobre el Medio Ambiente afirma «el hombre es, a la vez obra y artífice del medio que le rodea»; aunque utiliza la expresión «Medio Humano», a nuestro criterio restrictiva. La Declaración de Estocolmo engloba (el medio natural y humano o modificado por la humanidad) ambos esenciales. La Declaración de Estocolmo enfatiza que «la defensa y mejoramiento del medio humano para las generaciones presentes y futuras se ha convertido en reto imperioso de la humanidad». La Conferencia de Estocolmo, tuvo entre sus logros el surgimiento del programa de las Naciones Unidas para el Medio Ambiente (PNUMA) que fue creado en el año 1973, con el objetivo de proporcionar asistencia técnica a los gobiernos para la adaptación de medidas relativas al medio ambiente, la ayuda para la formación de personal especializado, ayuda financiera para fortalecer los organismos ambientales nacionales y regionales, apoyar programas de información y de educación ambiental. En general el PNUMA se creo para promover y fortalecer las políticas, las legislaciones y las instituciones ambientales en todo el planeta, contribuyendo a desarrollar las agencias y Ministerios del Ambiente, entre ellos el de Venezuela en 1977 y la Ley Orgánica del Ambiental de 1976. 
La Constitución Española de 1978 fue de las primeras en adoptar las recomendaciones de Estocolmo, proclamadas en su artículo $45^{25,26}$.

En la actualidad el Derecho ambiental se presenta como un Derecho fundamental del hombre, como una forma del derecho a la vida.

25 1. Todos tienen derecho a disfrutar de un medio ambiente adecuado para el desarrollo de la persona, así como el deber de conservarlo.

2. Los poderes públicos velarán por la utilización racional de todos los recursos naturales, con el fin de proteger y mejorar la calidad de la vida y defender y restaurar el medio ambiente, apoyándose en la indispensable solidaridad colectiva.

3. Para quienes violen lo dispuesto en el apartado anterior, en los términos que la ley fije se establecerán sanciones penales o, en su caso, administrativas, así como en la obligación de reparar el daño ocasionado.

26 En el marco del Derecho Constitucional comparado resaltan la Constitución de Brasil (1988), la Constitución de Colombia (1991), que dedican sendas capítulos a los derechos y deberes ambientales y diversas disposiciones esparcidas por sus títulos y secciones, seguidas por la Constitución de Paraguay y las actualizaciones de las Cartas de Argentina, Panamá, Guatemala y México, que tenía precedentes precursores este ultimo desde la Constitución de 1917, hasta la Constitución Venezolana de 1999, cuyos derechos ambientales y transgeneracionales son unos de los más avanzados, consecuencias innegables de creaciones en el ámbito parlamentario, institucional, de la investigación jurídica y de las luchas socioambientales. 